\title{
Editorial Questionnaire
}

Your comments are important to us. This form provides you with the opportunity to express your opinions. Our goal is to make CNS Spectrums your source for practical and clinical neuropsychiatric information. By filling out this Questionnaire, you enable us to incorporate your views about our editorial content in future issues. Please fill out this form in its entirety. Thank you.

Name (please print)

Address

\begin{tabular}{lll}
\hline City & State & Zip Code \\
\hline E-mail & Specialty
\end{tabular}

Signature

Date

Fax this form to 212.328.0600. E-mail to Im@mblcommunications.com. Or mail it to: CNS SPECTRUMS, MBL Communications, Inc., 333 Hudson Street, 7th Floor, New York, NY 10013

1. On a scale of 1 to 5 ( $1=$ Poor, $5=$ Excellent), please indicate your level of interest and/or satisfaction with the editorial content in this issue.

Cover Topic: Neuropsychiatric HIV Infection

$\square 1 \quad \square 2 \quad \square 3 \quad \square 4 \quad \square 5$

Departments

CNS Reports

$\square 1 \quad \square 2 \quad \square 3 \quad \square 4 \quad \square 5$

CME

$\square 1 \quad \square 2 \quad \square 3 \quad \square 4 \quad \square 5$

Point \& Commentary
$\square 1 \quad \square 2$
$\square 3 \quad \square 4 \quad \square 5$

2. Which areas of neuropsychiatry would you like us to cover in the future?

Please select any of the following
Teaching Monographs: CD-ROMs

$\square$ Pharmacologic Advances in the Treatment of ADHD

$\square$ The Use of Lithium in Bipolar Disorder

$\square$ Atypical Antipsychotics in the Treatment of Bipolar Disorder

$\square$ Comorbidity Issues Associated With ADHD
3. Please describe your reading pattern for this issue:

$\square$ Read cover to cover

$\square$ Skimmed table of contents

$\square$ Read select items of interest

$\square$ Skimmed text

$\square$ Did not read

4. On a scale of 1 to 5 ( $1=$ Incomplete, $5=$ Comprehensive), how would you describe the depth of coverage for this issue?

$\square 1 \quad \square 2 \quad \square 3 \quad \square 4 \quad \square 5$

5. Any other comments?

6. Please indicate your title:

$\square$ Psychiatrist

$\square$ Neurologist

$\square$ The 2003 Black Book of Psychotropic Dosing and Monitoring $\square$ The Diagnostic and Therapeutic Guide to Sleep Disorders

$\square$ The Effects of Antidepressants on Human Sexuality

$\square$ Dosing and Monitoring Guidelines: Mood Disorders

$\square$ The Side-Effect Profiles of Psychotropic Medications 


\section{Complimentary Subscription Form}

YES! I would like to continue my complimentary subscription to CNS SPECTRUMS

Name (please print)

Address

\begin{tabular}{lll}
\hline City & State & Zip Code \\
\hline E-mail & Specialty
\end{tabular}

Signature

Date

*Please complete all fields

Fax this form to 212.328.0600. E-mail to Im@mblcommunications.com. Or mail it to:

CNS SPECTRUMS

MBL Communications, Inc.

333 Hudson Street, 7th Floor

New York, NY 10013

\section{Complimentary Subscription Form}

\section{YES! I would like to continue my complimentary subscription to CNS SPECTRUMS}

Name (please print)

Address

\begin{tabular}{lll}
\hline City & State & Zip Code \\
\hline E-mail & Specialty
\end{tabular}

*Please complete all fields

Fax this form to 212.328.0600. E-mail to Im@mblcommunications.com. Or mail it to:

CNS SPECTRUMS

MBL Communications, Inc.

333 Hudson Street, 7th Floor

New York, NY 10013 


\section{Complimentary Subscription Form}

YES! I would like to continue my complimentary subscription to CNS SPECTRUMS

Name (please print)

Address

\begin{tabular}{lcc}
\hline City & State & Zip Code \\
\hline E-mail & Specialty
\end{tabular}

Signature

Date

*Please complete all fields

Fax this form to 212.328.0600. E-mail to Im@mblcommunications.com. Or mail it to:

CNS SPECTRUMS

MBL Communications, Inc.

333 Hudson Street, 7th Floor

New York, NY 10013

\section{Complimentary Subscription Form}

\section{YES! I would like to continue my complimentary subscription to CNS SPECTRUMS}

\section{Name (please print)}

Address

\begin{tabular}{lll}
\hline City & State & Zip Code \\
\hline E-mail & Specialty
\end{tabular}

*Please complete all fields

Date

Fax this form to 212.328.0600. E-mail to Im@mblcommunications.com. Or mail it to:

CNS SPECTRUMS

MBL Communications, Inc.

333 Hudson Street, 7th Floor

New York, NY 10013 


\section{Author Guidelines}

\section{Introduction}

CNS Spectrums is an Index Medicus journal that publishes original scientific literature and reviews on a wide variety of neuroscientific topics of interest to the clinician. CNS Spectrums will publish 12 issues in 2003 . As the immense prevalence of comorbid diseases among patients seen by psychiatrists and neurologists increases, these physicians will jointly diagnose and treat the neuropsychiatrically ill. Our mission is to provide these physicians with an editorial package that will enhance and increase their understanding of neuropsychiatry; therefore, manuscripts that address crossover issues germane to neurology and psychiatry will be given immediate priority.

\section{Scope of Manuscripts}

CNS Spectrums will consider the following types of articles for publication:

Original Reports: Original reports present methodologically sound original data.

Reviews: Reviews are overview articles that summarize and synthesize the literature on various topics in a scholarly and clinically relevant fashion. Suitable topics include mood disorders, schizophrenia and related disorders, personality disorders, substance-use disorders, anxiety disorders, neuroscience, psychosocial aspects of psychiatry, child psychiatry, geriatric psychiatry, and other topics of interest to clinicians. Original flowcharts designed to aid the clinician in diagnosis and treatment will be considered for publication in reviews and are encouraged.

Case Reports: Single or multiple case reports will be considered for publication.

Letters to the Editor: Letters will be considered for publication.

\section{Manuscript Submission}

General information: Two copies of the manuscript with a letter on the author's letterhead should be submitted to Jack M. Gorman, Editor (or, in Europe, to Joseph Zohar, International Editor), c/o MBL Communications, 333 Hudson Street, 7th Floor, New York, NY 10013; (F) 212.328.0600. Authors are also required to submit their manuscripts on computer disk in Microsoft Word format. Disks should be labeled with the word processing program, title of paper, and lead author's name. Accepted manuscripts and letters will he edited for clarity and style.

\section{Letters of permission to reproduce previously published} material: All material reproduced from previously published copyrighted material must be accompanied by a letter of permission from the copyright holder. All such material should include a full credit line (eg, in the figure or table legend) acknowledging the original source. Any citation of unpublished material or personal communication should also be accompanied by a letter of permission for anyone who is not an author of the paper.
Peer review: Authors must provide five names of parti-cularly qualified potential reviewers with no conflict of interest in reviewing the work. Contact information, including complete address, phone, fax numbers, E-mail address, and affiliations, should be included. The corresponding author will be notified by the editors when a decision regarding acceptance has been made. Peer review is anonymous.

\section{Manuscript Preparation}

Length: Reviews and Original Reports should not exceed 5,000 words (excluding References). Letters should not exceed 1,500 words. Single Case Reports should not exceed 3,750 words and may be submitted with a photograph, if applicable. Diagnostic/treatment algorithms (see Reviews) should contain an extensive introduction, flowchart or series of graphs that fill 8-12 journal pages, and a concise summary.

Spacing: One space should be left after commas and periods. Manuscripts should be double-spaced.

Abstract: Authors must provide a brief abstract.

References: American Medical Association style. See the following examples:

1. Jones J. Necrotizing Candida esophagitis. JAMA. 1980;244:2190-2191.

2. Stryer L. Biochemistry. 2nd ed. San Francisco, Calif: WH Freeman Co; 1980:559-596.

Continuing Medical Education: Authors must submit four multiple-choice questions (two Type A and two Type K), with answers.

Copyright: Materials are accepted for exclusive publication in CNS Spectrums and become the property of CNS Spectrums. Permission to reproduce material must be obtained from the publisher.

\section{Disclosure of Commercial Interests}

Authors must include a statement about all forms of support, including grant and drug company support. Such information may, at the editor's discretion, be shared with reviewers. If the article is accepted for publication, the editors will consult with the authors as to whether this information should be included in the published paper.

\section{Submission Checklist}

$\square$ Original manuscript plus one copy, with cover letter on author's letterhead

$\square$ Copies of permission letters to reproduce previously published and unpublished material

$\square$ A brief abstract of the article

$\square$ Four CME multiple-choice questions with answers

$\square$ Disk labeled with the word processing program, title of paper, and lead author's name

$\square$ Names and addresses of five potential reviewers 